\title{
Policies and Actions for Cancer Prevention: Food, Nutrition and Physical Activity
}

\author{
Kirsty Beck ${ }^{*}$, , Rachel L. Thompson ${ }^{1}$, Kate Allen ${ }^{1}$, Martin Wiseman ${ }^{1}$ and Michael Marmot ${ }^{2}$ \\ ${ }^{I}$ World Cancer Research Fund International, London, UK, ${ }^{2}$ University College London, UK
}

\begin{abstract}
The 2009 World Cancer Research Fund (WCRF) and the American Institute for Cancer Research (AICR) Report 'Policy and Action for Cancer Prevention' addresses the external influences on people's eating and physical activity habits over a lifetime, and evaluates possible actions to change these behaviours.

Estimates of preventability of cancer were calculated for USA, UK, Brazil and China. The estimates suggest that about 11 and 20 per cent of obesity-related cancers could be prevented, if everyone had a healthy weight.

The Report makes 48 recommendations, all with some relevance to overweight and obesity, for policies and actions to create environments which are conducive to healthy behaviours, thereby reducing risk of cancer directly, and indirectly through obesity. The recommendations are addressed to nine groups of actors-those people who take decisions or make policy at all levels. These groups are multinational bodies, civil society organisations, government, industry, media, schools, workplaces and institutions, health and other professionals, and people (as members of families and communities). All actors have a responsibility to give priority to public health, including prevention of obesity and cancer. Leadership is required from governments in particular to ensure a coherent and coordinated approach. All relevant actors need to work together so that initiatives are more likely to be successful and have lasting impact. The Report is intended as a starting point and a spur to action.
\end{abstract}

Keywords: Cancer, nutrition, physical activity, policy, prevention.

\section{INTRODUCTION}

\section{Background}

In 2007, the World Cancer Research Fund (WCRF) and the American Institute for Cancer Research (AICR) Report 'Food, Nutrition, Physical Activity, and the Prevention of Cancer: a Global Perspective' (the 2007 Diet and Cancer Report) was published [1]. The Report produced recommendations to reduce risk of cancer, presented as specific population goals and as personal recommendations for dietary and physical activity patterns, and for body weight.

The Report reviewed the body of evidence relating food, nutrition, and physical activity to cancer risk. Systematic literature reviews (SLRs) on 17 different types of cancer, as well as one on the determinants of obesity, were conducted according to a detailed set of instructions [2]. A panel judged the evidence according to its strength, quality, and quantity. The evidence was graded (based on the likelihood that a particular factor is either a cause of or protects against a specific cancer) as either 'convincing' or 'probable'; or if there was not adequate evidence as 'limited'. The main conclusions for overweight and obesity are summarised below.

\section{Body Fatness and the Risk of Cancer}

There was a convincing evidence that the greater the level of body fat, the greater the risk of cancers of the colon and rectum, oesophagus, pancreas, kidney, endometrium and

*Address correspondence to this author at the World Cancer Research Fund International, 19 Harley Street, W1G 9QJ, London; Tel: +44 (0) 207343 4200; Fax: +44 (0) 207343 4220; E-mail: k.beck@wcrf.org breast (in postmenopausal women) [1]. Being overweight or obese probably also increase the risk of gallbladder cancer.

\section{Determinants of Overweight and Obesity}

The review of the determinants of obesity is summarised in Table 1. The strongest evidence showed that regular and sustained physical activity of all types protects against weight gain, overweight and obesity.

Table 1. Factors that Modify the Risk of Weight Gain, Overweight and Obesity, Graded According to the Strength of the Evidence

\begin{tabular}{|c|c|c|}
\hline & Decreases Risk & Increases Risk \\
\hline Convincing & Physical activity & Sedentary living \\
\hline Probable & $\begin{array}{l}\text { Low energy-dense } \\
\text { foods } \\
\text { Being breastfed }\end{array}$ & $\begin{array}{l}\text { Energy-dense foods } \\
\text { Sugary drinks } \\
\text { 'Fast foods' } \\
\text { Television viewing }\end{array}$ \\
\hline
\end{tabular}

Source: Adapted from a matrix in the WCRF/AICR Report Food, Nutrition, Physical Activity, and the Prevention of Cancer: a Global Perspective [1], which also contains an explanation of the terms.

Low energy-dense foods, such as vegetables, fruits, pulses and wholegrains, which provide dietary fibre, are probably protective; correspondingly high energy-dense foods, and in particular sugary drinks and 'fast foods' are probably a cause of weight gain, overweight and obesity. Here, the term 'fast foods' is related to readily available meals, snacks, foods and drinks that tend to be high in energy, and in sugar, refined starches, fat or salt, and tend to 
be consumed frequently or in large portions. Television viewing, a particular form of sedentary living, was also associated with consumption of energy-dense foods. Energydense foods are usually high in fats or oils, processed starches or added sugars. Sustained breastfeeding probably protects infants and young children against excessive weight gain, and overweight and obesity tend to track into later childhood and adult life [1].

\section{Recommendations Relating to Body Fatness}

Factors graded 'convincing' or 'probable' formed the basis for the Panel's 10 recommendations in the form of public health goals and personal recommendations. The headline recommendation for body fatness is to be as lean as possible within the normal range of body weight. There are three personal recommendations regarding body fatness:

- Ensure that body weight through childhood and adolescent growth projects towards the lower end of the normal body mass index (BMI) range at age 21 ,

- Maintain body weight within the normal range from age 21 , and

- Avoid weight gain and increases in waist circumference throughout adulthood.

Quantified public health goals were also presented, as tools for policymakers and public health professionals to use in developing policy and monitoring progress. The public health goals of particular relevance to overweight and obesity are shown in Table 2 .

\section{The Aim of the Policy Report}

If the personal recommendations and public health goals from the 2007 Diet and Cancer Report were followed, much obesity and obesity-related cancers would be prevented. However, making personal recommendations and public health goals is just the first step towards this. It is just as important to understand how to achieve them. To this end, the aim of the current Policy Report, 'Policy and Action for
Cancer Prevention' [3] is to make recommendations for policies and actions that would help achieve the public health goals from the 2007 Diet and Cancer Report.

\section{NEED FOR ACTION}

At a global level patterns of disease are changing. Of great concern is the emergence of a double burden of disease in some populations where nutritional deficiencies are found alongside increasing levels of obesity and chronic disease [4]. In many areas around the world, including lower-income countries, with increasing urbanisation and globalisation of food systems, chronic diseases are becoming dominant.

\section{Why Prevention is Needed as Part of an Integrated Strategy}

In most populations, particularly since 1980 s, average body fatness has increased. Examples are shown in Fig. (1). In 2005 globally at least 1.6 billion people aged 15 and over were estimated to be overweight (with a BMI of over 25), and this number is projected to rise rapidly to 2.3 billion in 2015 [5, 6]. In 2005, at least 400 million adults were obese (with a BMI of 30 or more) and it is projected that this will rise to 700 million in 2015 [6].

Globally the number of cases of cancer is rising and the increase is predicted to continue. Recent estimates are that in 2007 there were 11.3 million new cancer cases and 7.9 million cancer deaths in 2007, with 15.5 million cases and 11.5 million deaths projected for 2030 [7]. Reasons for this projected increase include increasing global population, the ageing of this population and increased detection of cancers by screening programmes. The control of cancer by screening and early detection is essential, as are medical and surgical treatments. However, many cancers are detected at a late stage, and some cancers remain relatively unresponsive to treatment. Many middle- and low-income countries do not have adequate professional and material resources for universal treatment of cancer and other obesity-related health problems. As it is unlikely that such countries will gain these

Table 2. Selected Public Health Goal Recommendations Related to Body Fatness and Obesity from the 2007 Diet and Cancer Report

\begin{tabular}{|c|c|}
\hline $\begin{array}{c}\text { Body fatness, food and drinks that } \\
\text { promote weight gain }\end{array}$ & $\begin{array}{c}\text { Public Health Goal } \\
\text { The proportion of the population that is overweight or obese to be no more than the current level, or preferably } \\
\text { lower, in } 10 \text { years } \\
\text { populations }\end{array}$ \\
$\begin{array}{c}\text { Average energy density of diets to be lowered towards } 125 \mathrm{kcal} \text { per } 100 \mathrm{~g} \\
\text { Population average consumption of sugary drinks to be halved every } 10 \text { years }\end{array}$ \\
\hline Physical activity & $\begin{array}{c}\text { The proportion of the population that is sedentary to be halved every } 10 \text { years } \\
\text { Average physical activity levels (PALs) to be above } 1.6\end{array}$ \\
\hline Plant foods & $\begin{array}{c}\text { Population average consumption of non-starchy vegetables and of fruits to be at least } 600 \mathrm{~g} \text { (21 oz) daily } \\
\text { Relatively unprocessed cereals (grains) and/or pulses (legumes), and other foods that are a natural source of dietary } \\
\text { fibre, to contribute to a population average of at least } 25 \mathrm{~g} \text { non-starch polysaccharide daily }\end{array}$ \\
\hline Breastfeeding & The majority of mothers to breastfeed exclusively, for 6 months \\
\hline
\end{tabular}

Source: Food, Nutrition, Physical Activity, and the Prevention of Cancer: a Global Perspective, WCRF/AICR [1] 


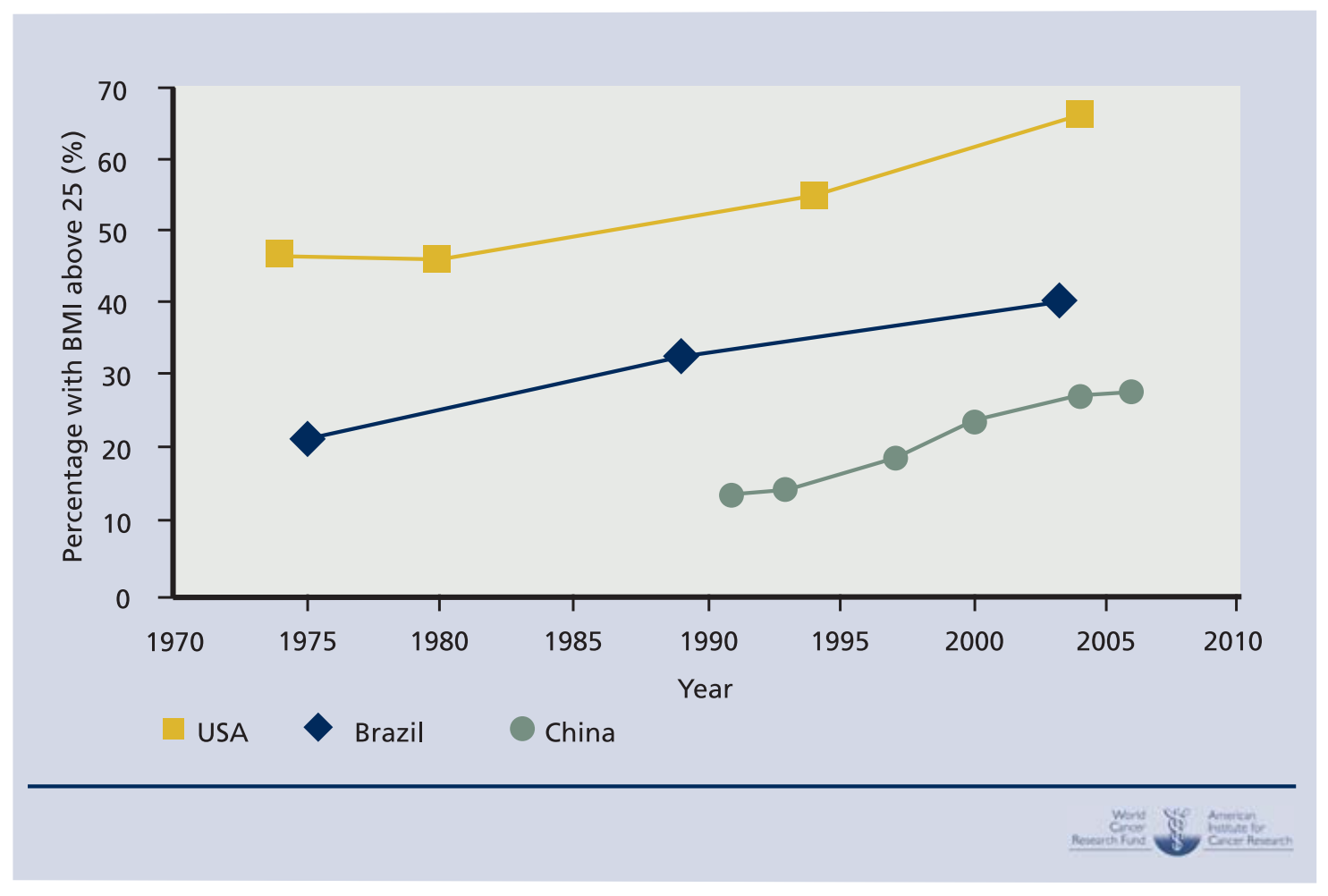

Fig. (1). Overweight and obesity. National trends for Brazil, China and the USA.

Source: Policy and Action for Cancer Prevention, WCRF/AICR [3].

resources, treatment of cancer and obesity is not a rational or feasible approach on a population basis in many places around the world. This can also be the case for impoverished populations living within some high-income countries.

\section{Adverse Trends for Determinants of Obesity}

Just as overweight and obesity are becoming increasingly common, so too is physical inactivity, itself a cause of excess body fatness. Average physical activity levels have declined as countries have become more industrialised and the proportion of people living in urban areas has risen. Sedentary ways of life are now dominant in most countries, including cities and urban areas of lower-income countries.

There are also observable adverse trends for other determinants of obesity. For example, in USA, between 1965 and 2002 , the amount of dietary energy from soft drinks in USA increased more than fourfold [8]. In a much shorter period of time, between 1999 and 2006, Mexican children aged between one and four years old more or less doubled their consumption of soft drinks [9].

Meeting the specified 2007 Diet and Cancer Report, public health goal (see Table 2) involves reversing existing trends in overweight and obesity as well as the determinants of these.

\section{Estimates of Preventability}

Prevention of cancer does not mean its total elimination, but reduction or delay in its occurrence, so that age-specific incidence is reduced. If cancer does appear, it is at a later age.

Estimates of the preventability of cancer are required by policy-makers in order to determine the likely impact of cancer prevention programmes. New estimates of how much cancer could be prevented by means of food, nutrition, and physical activity were produced for the Policy Report for two high-income countries (UK and USA), one middle-income country (Brazil) and one low-income country (China).

Preventability estimates for the seven cancers for which body fatness is a cause were calculated (see Table $\mathbf{3}$ ). Three sources of information were required to estimate preventability, the first was risk estimates for obesity and overweight compared with healthy weight for each of the seven cancers; this information was obtained from the 2007 Diet and Cancer Report [1]. Information on the prevalence of healthy weight, overweight and obesity was obtained from national surveys for each of the four countries. In order to estimate preventability across the seven cancer sites information on how common each cancer was in each country was obtained using GLOBOCAN 2002 [10]. A detailed description of the method can be found in the Policy Report [3]. These estimates show the proportion of cancers that could be prevented if everybody within the countries identified had a BMI of $<25 \mathrm{~kg} / \mathrm{m}^{2}$ (or BMI of $<23 \mathrm{~kg} / \mathrm{m}^{2}$ for pancreas and a BMI $<21 \mathrm{~kg} / \mathrm{m}^{2}$ for breast cancer). For the USA 19-20 per cent of all obesity related cancers could be prevented. The estimates for the other counties studied were lower; with the lowest being China (11-12 per cent) mainly due to the lower prevalence of overweight and 
Table 3. Estimates of Preventability (\%) by Appropriate Body Composition ${ }^{\mathrm{a}}$, for Cancers of which Body Fatness is a Cause, in Four Countries

\begin{tabular}{|c|c|c|c|c|c|c|c|c|}
\hline \multirow{2}{*}{ Cancer Site } & \multicolumn{2}{|c|}{ USA } & \multicolumn{2}{|c|}{ UK } & \multicolumn{2}{|c|}{ Brazil } & \multicolumn{2}{|c|}{ China } \\
\hline & Male & Female & Male & Female & Male & Female & Male & Female \\
\hline Oesophagus & 32 & 38 & 29 & 33 & 20 & 26 & 14 & 20 \\
\hline Pancreas & 34 & 25 & 32 & 19 & 25 & 14 & 20 & 10 \\
\hline Gallbladder & 11 & 28 & 8 & 21 & 3 & 15 & 2 & 10 \\
\hline Colorectum & 16 & 3 & 14 & 2 & 8 & 1 & 5 & 1 \\
\hline Breast & - & 17 & - & 16 & - & 14 & - & 12 \\
\hline Endometrium & - & 49 & - & 38 & - & 29 & - & 18 \\
\hline Kidney & 20 & 28 & 17 & 21 & 10 & 16 & 6 & 10 \\
\hline Total for these cancers combined & 20 & 19 & 18 & 16 & 13 & 13 & 11 & 12 \\
\hline
\end{tabular}

a. Based on the conclusions of the 2007 WCRF/AICR Diet and Cancer Report [1].

Source: Policy and Action for Cancer Prevention, WCRF/AICR [3]

obesity. With the rising global rates of obesity, the potential impact of obesity on the risk of cancer will increase in the future.

It was not possible to obtain country specific incidence of breast cancer by menopausal status and hence, the estimates relate to total breast cancer. As increased body fatness is a cause of postmenopausal breast cancer only, the figures for breast cancer are likely to be overestimated though only slightly, as premenopausal breast cancer is relatively uncommon. Total oesophageal cancer was used rather than histological sub-types. Body fatness is a cause of adenocarcinoma and hence, in the countries with a large proportion of squamous cell carcinoma this will lead to an overestimate of the impact of BMI.

\section{The Challenge - Personal Choice and its Limitations}

In most parts of the world, particularly in lower-income countries and also among disadvantaged populations within higher-income countries, the extent to which people can make informed personal choices in order to prevent disease, including obesity and cancer, is restricted. Even for affluent groups, simply knowing what are healthy ways of life may not lead to these being adopted. External factors constrain people's ability to choose healthy ways of life. For instance, people generally do not deliberately choose to be obese, and yet more than half of the adult populations of USA and many European countries are overweight or obese. The Foresight project concluded that "for an increasing number of people, weight gain is inevitable - and largely involuntary consequence of exposure to a modern lifestyle. This is not to dismiss personal responsibility altogether, but to highlight a reality that the forces that drive obesity are, for many people, overwhelming" [11].

The production and consumption of food and drink, and patterns of physical activity and obesity, and therefore risk of cancer, are affected by environmental, economic and social factors, sometimes referred to as "the causes of the causes". These are broad categories and there is a considerable overlap between them. There is also an overlap between the global, national, local and personal levels at which these factors operate.

The concept that the personal behaviours that determine dietary and other exposures which influence the risk of obesity or of cancer or both, are shaped not only by deliberate choice, but also, and perhaps to a greater extent, by the complex interplay of these "upstream" factors is illustrated by the conceptual framework in Fig. (2). More complex frameworks exist that have been developed specifically to depict the relationships between different causes of obesity $[11,12]$. The conceptual framework in Fig. (2) was developed for factors that specifically affect the risk of cancer, including, but not limited to those that affect body fatness.

Personal and population risk of cancer is mostly determined by external factors. This figure illustrates that many factors influence patterns of food and drink consumption, physical activity, and breastfeeding. These factors can be broadly categorised as being in the dimensions of the physical environment or of economic or social drivers. However, there is a substantial overlap between the categories (depicted by the graduation in colour in the horizontal green bar). These factors may operate at a global, national, or local level. Again, there can be overlap between these levels (indicated by gradual change in shade from top to bottom). As experienced at a personal level, these factors impact on the accessibility, affordability, and acceptability of foods and drinks, breastfeeding, and physical activity.

Current policies already shape people's behaviours even if unintentionally, and some may even damage public health in the long term. For example, subsidies for production of corn in North America make high-fructose corn syrup, and therefore soft drinks sweetened with this syrup, artificially cheap, which encourages consumption [13]. The improvement and protection of public health does not happen by accident - it requires deliberate policies and actions. To be effective, prevention requires a new appreciation of the nature and role of external factors that protect against or are causes of obesity and cancer. 


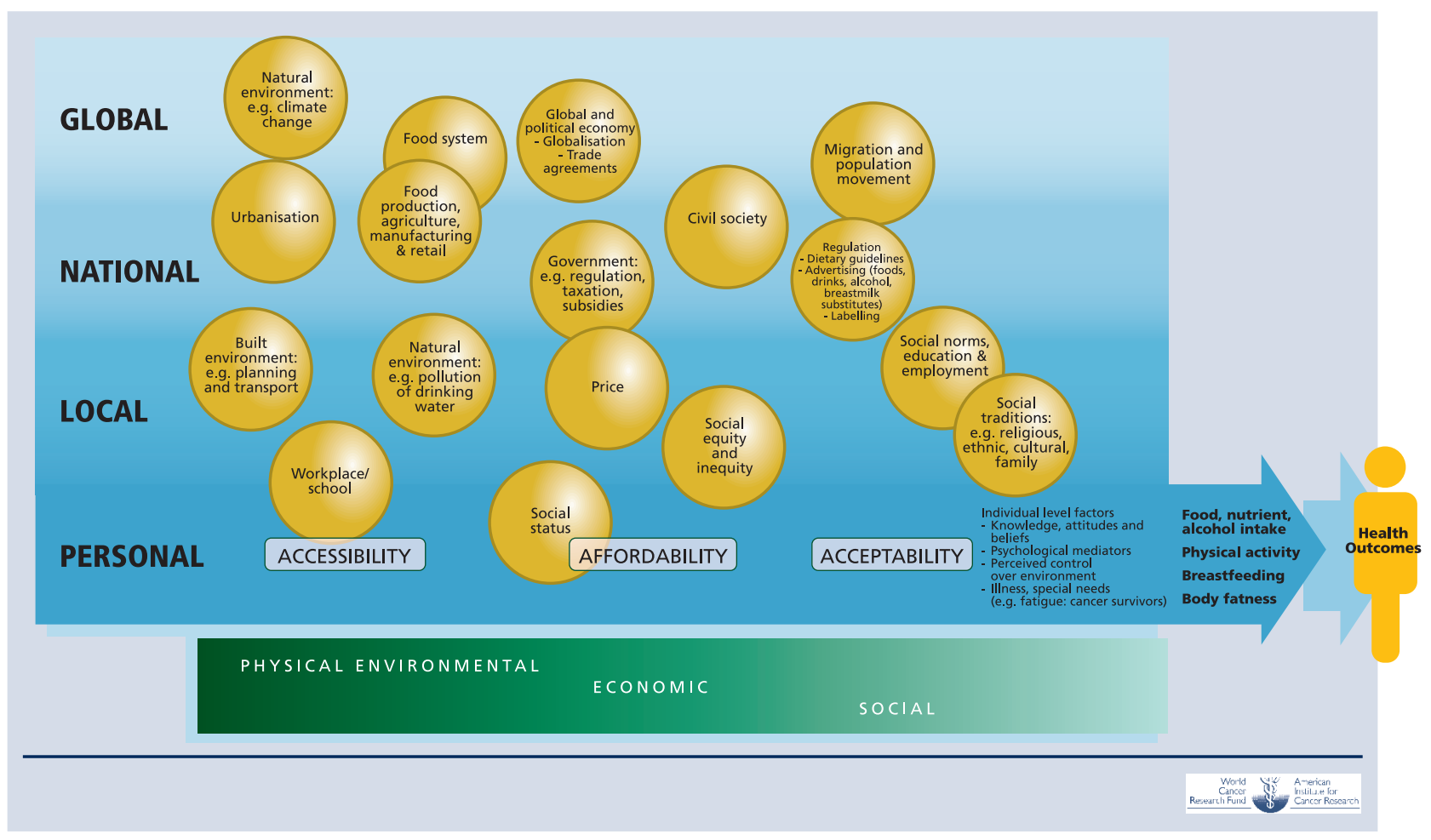

Fig. (2). Factors that affect the risk of obesity and cancer: a conceptual framework.

Source: Policy and Action for Cancer Prevention, WCRF/AICR [3].

\section{EVIDENCE AND EVALUATION}

\section{Methodology of the Report}

An independent Panel of 23 international experts considered the evidence. Two systematic reviews of predominantly epidemiological and public health literature were commissioned from independent research institutions. The first reviewed the evidence for external factors that might influence dietary patterns and physical activity levels, and obesity. It also reviewed evidence relating to population level interventions aimed to change or maintain behaviour. The second reviewed the effectiveness of individual level interventions to prevent cancer through food, nutrition, or physical activity. In order to be as comprehensive as possible, additional information obtained from Panel members and reviewers was also used. A special effort was made to locate research and other evidence from lower-income countries.

Potential opportunities for action identified through this process were then evaluated. The evaluation criteria included the likely political feasibility and acceptability of new policies and actions; their potential impact; possible benefits and harms, general acceptability, cost, the timeframes needed to move from agreed policies to actions, and their transferability to different settings.

There are several limitations of this type of review. The literature comes from an extensive range of disciplines, and much is in the form of studies whose results are hard to compare directly. Most of the more rigorous studies have been carried out in countries with the resources available for this type of research, in particular USA and European countries.

The main findings from the evidence are described below, categorised within four broad dimensions - physical environmental, economic, social or personal (see Fig. 2). The summary presented here focuses on the evidence relevant to factors associated with overweight and obesity. Actions that have a potentially high impact are highlighted in Table 4.

These actions were identified as part of the evidence review for the Policy Report [3] as being of potentially high impact if implemented. They are not recommendations themselves. They comprise a variety of different types of action, some of which are clearly more achievable than others.

\section{The Physical Environmental Dimension}

The physical environment refers to climate, terrain, land use and agriculture, and the built environment.

\section{Climate}

Climate change could have a substantial effect on global production of food. Research into climate change needs to examine and project its likely impact on food security and on consequent risk of disease, including obesity and cancer.

\section{Food Production}

Food production and methods of farming determine the types and amounts of foods consumed, such as non-starchy vegetables and animal fats. Encouragement of smallholdings and home farms and gardens can increase availability of 
Table 4. Actions with Potentially High Impact

\begin{tabular}{|c|c|}
\hline & Actions with potentially high impact \\
\hline Physical environmental dimension & $\begin{array}{l}\text { Making breastfeeding pleasant within built environments } \\
\text { Increasing freely accessible parks and leisure areas } \\
\text { Creation and revival of active transportation systems }\end{array}$ \\
\hline Economic dimension & $\begin{array}{l}\text { Use of global trade rules specifically and explicitly to improve public health } \\
\text { Removal of agricultural and other subsidies that tend to damage public health, } \\
\text { Imposition or increase of taxes and other disincentives on unhealthy foods and drinks } \\
\text { Reformulation of processed foods and drinks to contain less sugar, refined starches, fat and salt } \\
\text { Reduction of portion sizes of processed foods and drinks. } \\
\text { Restriction or prohibition of advertising and marketing of unhealthy processed foods and drinks to children } \\
\text { Controls on advertising and marketing of infant formula and weaning foods } \\
\text { Reduction of absolute poverty and of income inequities }\end{array}$ \\
\hline Social dimension & $\begin{array}{l}\text { Promotion of a culture of breastfeeding } \\
\text { Introduction or strengthening of academic and practical nutrition and physical activity in school curricula } \\
\text { Restriction of access to unhealthy foods, drinks and snacks in schools, other institutions and workplaces } \\
\text { Provision of facilities for breastfeeding in workplaces } \\
\text { Legislation to protect and improve population nutrition and physical activity, control obesity } \\
\text { Regulation of policies on food, nutrition and physical activity in schools and other institutions } \\
\text { Maintenance of the healthy aspects of traditional ways of life } \\
\text { Reduction of social inequities }\end{array}$ \\
\hline Personal dimension & Promotion of interventions that include support from knowledgeable family members \\
\hline
\end{tabular}

vegetables and fruits. Intensive systems of industrial animal production involving rapid weight gain in cattle, pigs, and poultry produce meat with higher energy from fat, and increased ratios of saturated to unsaturated fatty acids [14, 15]. These intensive farming methods can increase the availability and affordability and thus consumption of meat and processed meat relatively high in fat.

\section{Retail and Catering Environments}

The location of supermarkets affects the accessibility and availability of foods and drinks. Studies in higher-income countries suggest that the presence of supermarkets in a neighbourhood is associated with a lower incidence of overweight and obesity and may bring about small improvements in intakes of vegetables and fruits [16, 17]. However, supermarkets can also increase access to energydense processed foods. The availability and positioning of healthy foods and drinks within supermarkets, and other retail and catering outlets, is important [18]. Evidence from lower-income countries is lacking. It is hard to predict with confidence the possible impact of such retail outlets on traditional food patterns, physical activity and body fatness in these settings.

\section{Planning and Transport}

There is a substantial and consistent evidence that approaches designed to make cities safe and pleasant for pedestrians and cyclists, both in streets and also in open spaces within cities, are effective in increasing average levels of physical activity $[19,20,21]$. Major investments in accessi- ble and affordable sports and recreation facilities appear to increase physical activity levels.

Breastfeeding is easier when public facilities, such as shopping centres, travel stations, restaurants, and workplaces, are laid out in a way that offers pleasant and safe environments for breastfeeding or for expressing milk [22]. Environmental factors important in supporting breastfeeding in the work setting include a suitable, dedicated room with a refrigerator and the means to sterilise equipment and allow safe storage of expressed milk, and access to a crèche [23, 24].

\section{The Economic Dimension}

The evidence shows that fiscal policies and actions have a major impact on the nature and quality of the foods and drinks people purchase and consume.

\section{Economic Globalisation}

Economic globalisation together with urbanisation has resulted in the homogenisation of food supplies, increased intake of vegetable oils, 'fast foods', sugary drinks and often alcoholic drinks, and meat and meat products, and a reduction in the intake of whole grains, fibre, pulses, vegetables, and fruits. These factors directly or indirectly increase the risk of obesity and a number of common cancers.

The acceleration of world-scale trade in food, and its manufacture, distribution, marketing, and sale, greatly strengthens transnational food companies [25]. This may increase the available variety of foods and drinks, but 
generally makes food supplies more processed and higher in energy [25-29].

National and international agricultural policies can affect the availability and prices of different foodstuffs. Policies often encourage the production of cereals, dairy products, sugar, and beef but rarely of fruits, vegetables, nuts, pulses, whole grains, and healthy oils [30, 31].

\section{Availability and Price}

The production and sale of foods and drinks are not a matter of simple supply and demand. Increasing the availability and decreasing the price of healthy foods increase the amounts consumed, and decreasing the availability and increasing the price of snack foods decrease the amounts consumed [32-34]. However, policies and interventions that affect the price, availability, and accessibility of foods and drinks are rarely devised with public health in mind. Policies can include agriculture support systems that reduce costs to producers and manufacturers and often also to the consumer. For example, agricultural policies that subsidise meat or dairy products directly, or indirectly through cheaper animal feed, make these foods cheaper and tend to increase the amounts purchased and consumed $[35,36]$. Removal of such subsidies has the reverse effect.

Conversely, pricing policies can also include taxation that artificially increase the price of foods and drinks. Mexico is considering the imposition of taxes on the fat content of milk and foods, and the sugar content of soft drinks [12]. In USA in 2000, there were 11 local taxes on soft drinks and eight further taxes targeted at snacks or confectionery (candy) [37].

Exercise referral schemes (where exercise facilities are offered at no cost for a fixed period) can be effective among those who complete the schemes, but dropout rates are high and positive effects on physical activity tend to be short term [38-40]. Exercise referral may be more effective for those who are overweight but not obese, and for those initially not completely sedentary $[38,39]$.

\section{Food and Drink Processing}

Reformulation of processed foods and drinks to lower the energy level, as well as reducing portion sizes of these products, can be an effective way to reduce energy consumption, especially when supported by simple, uniform and explicit nutrition product labelling. The evidence suggests that new schemes are more accepted if accompanied by information and education campaigns [41].

\section{Product Advertising and Marketing}

Food advertising and marketing, generally for processed 'fast food', and other convenience foods, and for sugary drinks, influence the choice of foods and drinks. The evidence is particularly strong for causal links between television advertising for, and the choice of, processed foods and sugary drinks, in particular for advertising aimed at children [42-44]. Though most evidence comes from high-income countries, this is supported by evidence from lower-income countries. Similarly, evidence suggests that marketing of infant formula has a negative impact on breastfeeding [4547].
Publicly funded promotion of healthy foods and drinks is likely to be effective if well resourced and sustained [48]. The evidence is mixed for campaigns to promote active travel, but indications are that targeting motivated subgroups can improve effectiveness $[49,50]$.

\section{Income Status and Equity}

Generally the more money people have the greater choice they have in the foods that they can purchase and consume. As income decreases, purchases and consumption of processed foods increases. Families on lower incomes select cheap 'filling' foods in order to obtain their energy needs. Lower-income households tend to have a lower consumption of fruits, vegetables, meat, and dairy products and higher consumption of cereals, sweets, and added fats. Lower socioeconomic status is associated with poor general diet quality [51-54]. Evidence on income and income disparity is difficult to interpret. Much depends not only on the absolute degree of prosperity or poverty but also on the differential rates between people within societies, and on the setting. Prosperity and poverty are relative as well as absolute, and in many settings income itself is not a good indicator of health status.

\section{The Social Dimension}

The social dimension refers to ethnic background, culture, religion, families and environments such as schools and workplaces.

\section{Ethnicity and Culture}

Culture and values shape people's ways of life. For example, social attitudes to body fatness and physical activity vary with ethnic background [55-60]. Public perceptions of acceptability of long-term breastfeeding influence its duration, although breastfeeding rates vary inconsistently with ethnic group [61, 62]. Promotion and protection of traditional social factors that lead to healthy lifestyles can be important. For example, in South Korea rates of overweight and obesity remain lower than in countries of comparable average income. This is thought to be because the country has protected its traditional food systems, which is relatively high in vegetables and low in fat [63]. The South Korean government has taken the lead on this, together with professional and civil society organisations [64].

\section{School and Work}

Children spend much of their time at school, as do employed adults at work. What is eaten at school and in the workplace, and the amount of physical activity in these settings, make up a substantial proportion of overall diets and physical activity. The quality of foods and drink available in the workplace, together with opportunities for employed mothers to breastfeed, and for physical activity are important.

It is important that in schools the curriculum includes nutrition and physical activity, and that healthy food is available at lunch, and in tuck shops and vending machines if these are present. The evidence suggests that school-based interventions that make healthy options available and restrict the availability of less healthy alternatives can be effective 
[65]. School-based interventions appear to be more effective when they address the wider context and involve the whole community, and if they are supported by governments and enacted as formal regulations [66].

\section{Social Status and Equity}

Increased social equity is likely to reduce rates of chronic disease. Higher social status usually brings better education, more money and greater access to pleasant and rewarding activities. Conversely lower social status limits choice. Reducing and sustaining reduction in social inequities at any level requires continued political will and committed partnership of all actors.

\section{Civil society, Multinational Bodies and Government}

There are good evidences from other public health related contexts, such as smoking and the environment, that support and leadership of civil society organisations (CSOs) is important for the success of any major public health programme.

Government interventions have taken the form of legal and fiscal measures designed to make healthy choices more affordable, accessible, and acceptable. Interventions that are sustained and supported by all interested groups, including government at appropriate levels, the media, industry, and public interest or professional groups can be effective.

\section{The Personal Dimension}

The personal dimension includes personal knowledge, attitudes and beliefs, and health status, and includes consideration of people as members of families or local communities.

\section{Individuals, Families and Communities}

The evidence suggests that interventions are more likely to be effective and sustained when they involve people as members of families, or involve friends, close-knit communities, and other groups such as clubs $[67,68]$. For example, involving fathers in breastfeeding education improves breastfeeding rates [69] and parental and social support increases physical activity levels among children [70]. Addressing people as individuals appears less likely to be effective and less likely to have a sustained effect.

Knowledge, Attitudes and Beliefs
Adequate knowledge of what constitutes healthy patterns of diet and physical activity, and of healthy body weight are essential but alone may not lead to changes in behaviour. Knowledge, attitudes, and beliefs are only inconsistently associated with degrees of physical activity $[60,61]$ and body fatness as measured by BMI [71, 72]. Effective programmes include education and information components as part of concerted action, supported in the family and community by health professionals $[73,74]$.

The evidence implies that breastfeeding is most likely to be sustained when advice on its benefits is given during antenatal and postnatal periods $[75,76]$.

\section{Physical and Psychological States}

Physical and psychological states shape patterns of diet, physical activity, and body composition, and also patterns of breastfeeding. For example, people with low self-esteem may be less likely to decrease weight in response to encouragement to do so [77]; emotional support programmes increase initiation and duration of breastfeeding [22]. Policies and practices applied without consideration of the differences between populations or people are less likely to be effective.

\section{Personal Characteristics}

Age, sex and weight all influence patterns of diet, physical activity, and body composition. For example, young people, and boys and men, are more likely to take part in recreational physical activity than older people, or girls and women $[60,78,79]$. The evidence shows that protection against chronic diseases including cancer best begins at the start of life. Policy-makers, investigators, health professionals, and people themselves will be more likely to succeed in maintaining healthy habits and changing unhealthy habits when they take these factors into account within a life course approach.

\section{RECOMMENDATIONS}

The evidence collected for the Policy Report, together with that from the 2007 Diet and Cancer Report, was used as a basis for producing the 48 recommendations of the Policy Report. All have some relevance to overweight and obesity. A recommended policy or action may aim to decrease consumption of energy-dense foods, or of sugary drinks, or

Table 5. The Policy and Action Recommendations, by Actor

\begin{tabular}{|c|c|}
\hline & Recommendations \\
\hline $\begin{array}{l}\text { Multinational } \\
\text { bodies }\end{array}$ & $\begin{array}{l}\text { All multinational bodies: Build the protection and maintenance of public health into all relevant agriculture, food, health, economic, trade, } \\
\text { environmental and other agreements } \\
\text { UN bodies: Work together to ensure integrated policies among all relevant agencies }\end{array}$ \\
\hline \multirow{5}{*}{$\begin{array}{l}\text { Civil society } \\
\text { organisations } \\
\text { (CSOs) }\end{array}$} & $\begin{array}{l}\text { All civil society organisations: Create, develop, and press governments and other actors to implement effective policies and programmes } \\
\text { for nutrition and physical activity }\end{array}$ \\
\hline & $\begin{array}{l}\text { Civil society organisations concerned with public health: Hold other actors to account regarding their policies and actions on food, } \\
\text { nutrition, and physical activity, including the prevention of cancer }\end{array}$ \\
\hline & $\begin{array}{l}\text { Civil society organisations concerned with public health: Mobilise the media and public opinion in support of improved public health, } \\
\text { including healthy nutrition, sustained physical activity, and the prevention of cancer }\end{array}$ \\
\hline & $\begin{array}{l}\text { Civil society organisations concerned with public health: Form alliances with associated civil society organisations including those } \\
\text { concerned with public policy, justice, equity, and environmental protection }\end{array}$ \\
\hline & $\begin{array}{l}\text { Civil society organisations concerned with public health: Advocate traditional cultures and ways of life when these generate healthy, } \\
\text { diverse, and sustainable dietary patterns and regular physical activity }\end{array}$ \\
\hline
\end{tabular}


(Table 5) Contd.....

\begin{tabular}{|c|c|}
\hline & Recommendations \\
\hline Government & $\begin{array}{l}\text { Examine, audit, and revise legislation and regulations so that they protect public health and prevent disease, including cancer } \\
\text { Ensure that built and external environments are designed and maintained in ways that facilitate physical activity and other healthy behaviour } \\
\text { Encourage safe, nutrient-dense, and relatively unprocessed foods and drinks, and discourage sugary and alcoholic drinks and 'fast' and other } \\
\text { processed foods } \\
\text { Require schools to provide meals to high nutritional standards, and facilities for recreation and sport, and to include nutrition and physical activity in } \\
\text { core curricula } \\
\text { Require all government and publicly funded facilities that provide catering to ensure that their meals, foods, and drinks are of high nutritional quality } \\
\text { Require widespread dedicated walking and cycling facilities throughout the built and external environment } \\
\text { Restrict advertising and marketing of 'fast' and other processed foods and of sugary drinks to children, on television and in other media and in } \\
\text { supermarkets } \\
\text { Incorporate United Nations recommendations on breastfeeding into law or appropriate public health and consumer protection rules } \\
\text { Give greater priority to research on, and programmes to improve, public health, including the prevention of cancer and other diseases } \\
\text { Establish and maintain publicly funded information and education on, and surveillance of, food, nutrition, and physical activity status } \\
\text { Ensure that international food trade and aid sustains future health as well as the immediate relief of populations in recipient countries }\end{array}$ \\
\hline Industry & $\begin{array}{l}\text { Built environment industries: Plan, commission, construct, and operate all built environments so as to protect public health and facilitate physical } \\
\text { activity } \\
\text { Food and drink industries: Make public health an explicit priority in all stages of food systems including product research, development, formulation } \\
\text { and reformulation, and promotion } \\
\text { Food and drink industries: Ensure that healthy meals, snacks, foods, and drinks are competitively priced compared with other products } \\
\text { Food and drink industries: Collaborate in order to stop advertising, promotion, and easy availability of sugary drinks and unhealthy foods to children } \\
\text { Food and drink industries: Ensure that marketing and promotion of breastmilk substitutes and complementary foods follow the terms of UN codes } \\
\text { and strategies on infant and young child feeding } \\
\text { Food and drink industries: Ensure accuracy, uniformity, and availability of product information in all advertising and promotion and on food labels } \\
\text { Physical activity industry: Promote goods and services that encourage participation in physical activity by people of all ages, rather than in } \\
\text { competitive or elite sporting performance } \\
\text { Entertainment and leisure industry: Give higher priority to entertainment products and services that enable everybody, especially children and young } \\
\text { people, to be physically active }\end{array}$ \\
\hline Media & $\begin{array}{l}\text { All media: Emphasise news, features, and campaigns designed to promote public health and to prevent cancer, and put health coverage in context } \\
\text { All media: Give executives resources and authority to ensure that their writers and editors have, or know how to access, expertise in public health } \\
\text { All media: Distinguish between news and editorial coverage, and advertisements and other commercially sponsored material } \\
\text { Advertising and publicity media: Advise clients against campaigns that make misleading or unsubstantiated claims, or that promote unhealthy diets, } \\
\text { physical inactivity, or overweight and obesity }\end{array}$ \\
\hline Schools & $\begin{array}{l}\text { Provide healthy daily meals for all staff and pupils, together with facilities for active recreation, activity and sports } \\
\text { Incorporate food and nutrition (including food preparation and cooking skills) and physical education into the mandatory core curriculum } \\
\text { Ensure that teaching materials are independently originated and free from commercial bias } \\
\text { Do not allow vending machines that offer snacks high in sugar, fat or salt, or sugary drinks and withdraw such 'fast' foods and drinks from school } \\
\text { canteens }\end{array}$ \\
\hline $\begin{array}{l}\text { Workplaces } \\
\text { and } \\
\text { institutions }\end{array}$ & $\begin{array}{l}\text { Workplaces and institutions: Use price and other incentives to encourage healthy eating and active commuting, and to discourage motorised transport } \\
\text { Workplaces and institutions: Ensure that physical environments are designed or adapted and maintained to facilitate physical activity and weight } \\
\text { control } \\
\text { Workplaces and institutions: Encourage sustained breastfeeding with supportive environments and employment contracts, and access to childcare } \\
\text { Workplaces and institutions: Do not allow vending machines that offer snacks high in sugar, fat or salt, or sugary drinks, and withdraw such 'fast' } \\
\text { foods and drinks from canteens } \\
\text { Institutions: Provide healthy meals, facilities for physical activity, and access to advice on nutrition, fitness, weight control, and disease prevention }\end{array}$ \\
\hline $\begin{array}{l}\text { Health and } \\
\text { other } \\
\text { professionals }\end{array}$ & $\begin{array}{l}\text { All professionals: Include food, nutrition, physical activity, and cancer prevention in core professional training and continuing development } \\
\text { All professionals: Work with other disciplines to help understand how to improve public health, including cancer prevention, through food, nutrition, } \\
\text { and physical activity } \\
\text { Health professionals: Prioritise public health including cancer prevention, and food, nutrition, and physical activity, in core training, practice, and } \\
\text { professional development } \\
\text { Health professionals: Take a lead in educating and working with colleagues, other professionals, and other actors to improve public health including } \\
\text { cancer prevention } \\
\text { Health professionals: Involve people as family and community members, and take account of their personal characteristics in all types of professional } \\
\text { practice }\end{array}$ \\
\hline People & $\begin{array}{l}\text { Support organisations and initiatives whose purpose is to improve public and personal health and to prevent chronic diseases including cancer } \\
\text { Develop policies and set examples within the household and community to enable healthy eating, sustained physical activity, and weight control } \\
\text { Ensure that personal, household, family, and community good health and protection against disease are priorities when making major decisions } \\
\text { Use independent nutrition guides, food labels and other reliable information when planning household supplies and purchasing food and drink }\end{array}$ \\
\hline
\end{tabular}

Source: Adapted from Policy and Action for Cancer Prevention, WCRF/AICR [3].

sedentary living; or to increase consumption of low energydense foods and dietary fibre, to increase physical activity, or encourage breastfeeding; or combinations of these. The 48 recommendations are shown in Table $\mathbf{5}$.

The recommendations are addressed to actors-those people who make decisions or policy at all levels from
United Nations agencies to families. The nine groups of actors are described below. They cover a range of settings or activities within global society, and all of them are important. Achieving sustained impact from the recommendations depends on concerted and integrated action from all sectors in society (see Fig. 3). 
Achieving healthy patterns of diet and sustained physical activity requires concerted and integrated action from all sectors of society. The recommendations are directed at nine groups of actors. The impact of policies and actions depends on successful interactions between all the actors. Each recommendation does not stand alone; all depend to some extent on action being taken elsewhere. In some cases one action depends on another; in others the benefit from two or more actions will be greater than the sum of them separately- this is to say 'synergistic'.

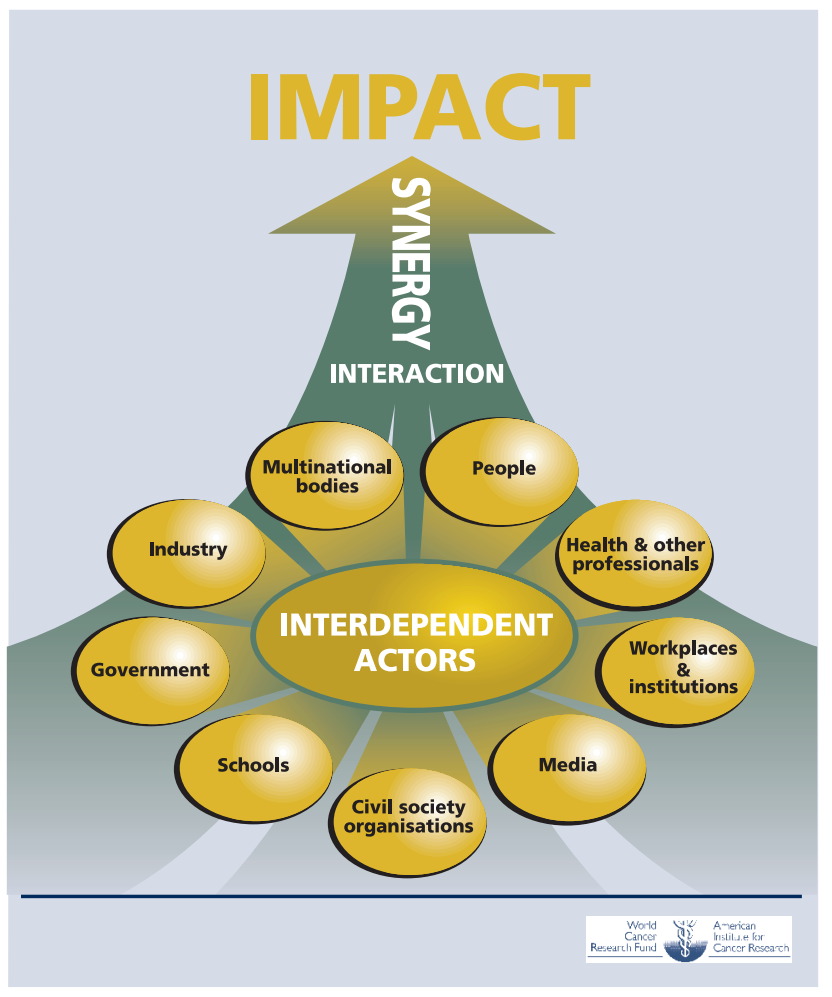

Fig. (3). The nine actors: impact of concerted action.

Source: Policy and Action for Cancer Prevention, WCRF/AICR [3].

\section{Multinational Bodies}

In this context, multinational bodies include the United Nations (UN) organisations as well as international political, economic and trade groups such as the World Trade Organization.

UN and other multinational bodies concerned with agriculture, food, and health have considerable influence on public health. The opportunities indicated in the recommendations are for UN bodies to give a higher priority to the promotion of public health, including the prevention of obesity and cancer, and to work together more effectively to ensure integrated policies and actions.

The prevention and control of cancer and other chronic diseases is a challenge affecting the whole world, and so needs to be addressed at an international level. Prevention of both obesity and cancer need to be central considerations when international political, economic, trade, and other relevant policies are determined.
Global strategies such as those now agreed within the UN system on diet and physical activity and infant and young child feeding are vital. In order for these, and strategies specifically for the prevention of cancer, to be fully effective they must be an integral part of coordinated public health strategies designed to prevent and control other diseases.

\section{Civil Society Organisations (CSOs)}

This group includes international and national CSOs such as public interest and consumer representative organisations, as well as charitable foundations, scientific and professional associations, trade unions, religious groups, and smaller farming and fishing cooperatives.

Many types of CSO work in ways that may affect public health and many leading and effective CSOs are concerned specifically with food and nutrition. Civil society is important for cancer prevention because politicians and civil servants increasingly depend on it to advise on public policies and actions and to draft legislation. Equally, policies and actions proposed by multinational bodies, governments, or industry often need support from CSOs in order to succeed.

CSOs can also play an important role in holding other actors to account but it is difficult for individual organisations to do this on their own and this is why alliances of likeminded organisations are recommended.

\section{Government}

The recommendations are aimed not just at government departments responsible for health, food and agriculture but also others such as employment, sport, education and planning and development. Government includes not only national, but also regional, local or other subnational levels.

Government has a special role to play when it comes to public health. Governments are responsible for providing political and social context that is conducive to the health of their citizens. The evidence consistently shows that pricing and other fiscal policies affect affordability and availability of products. Policies also need to include regulation to ensure explicit labelling of processed foods and drinks.

Governments at all levels need to be lead partners with other actors in requiring that built an external environments for which they have direct responsibility are designed and operated with health in mind.

\section{Industry}

These recommendations are aimed at decision-takers in relevant industries, at local, national and international levels. These industries include foods and drinks, urban and rural planning and development, construction and engineering, and entertainment, leisure, and sports. For all these groups, this Report proposes that a new balance is struck in favour of health.

The needs of public health as now generally understood and accepted are often not yet a priority for relevant industries. Industrial policies and practices need to be designed and carried out with public health, including prevention of cancer, in mind. 


\section{Media}

This group includes electronic, broadcast, print and other editorial, features, entertainment, and advertising media.

The media is a major source of information for people, which means it plays an important role in making people sure to know what affects their cancer risk. Health is already a popular topic in the media, but sometimes a distorted view of the evidence is given. This recommendation does not mean to restrict reasonable debate and controversy. But it is also important that when minority views that challenge wellfounded evidence are reported, it is made clear to what extent the scientific community supports such views, if at all.

\section{Schools}

This group refers to primary and secondary schools, and to nurseries and other pre-schools. It is aimed at governors, executives, teachers, and other staff both in their professional capacity and as role models for their pupils. Schools are important for cancer prevention because after the family, they usually have the greatest influence on children. They often shape habits and ways of life that last into adult life.

\section{Workplaces and Institutions}

The term "institutions" includes universities and other places of higher education, hospitals, hostels, care homes, the armed forces and prisons. The duty of care for these institutions is as clear-cut as in schools. For example, people who are in hospital or in prison are largely or completely dependent on these institutions for catering and physical activity facilities.

\section{Health and Other Professionals}

This group includes all professionals, usually formally qualified in their field, and their professional bodies who may have an impact on public health, and cancer in particular.

Health professionals have a direct and obvious influence on people's health. Medical doctors in particular are trusted by the public and expected to be qualified to give advice on prevention of disease as well as diagnosis and treatment.

Other professionals can also have a major impact on public health. Two examples of this are architects and engineers, who are responsible for the built environment. Also, professionals whose practice shapes food systems include environmentalists and food scientists, while teachers and journalists educate and inform about health.

\section{People}

This group includes people as members of close knit social groups and family members. The personal recommendations for reducing cancer risk are included in the 2007 Diet and Cancer Report, but the latest Report addresses the responsibilities people have for others as parents and citizens.

In any society, people do not make decisions in isolation. For example, the decisions people take in buying food shopping can impact on their family.

A fundamental aspect of public health is that ultimately it is people who make the difference in society as members and leaders of groups. Individual consumer demand is not the only or even the main driving force driving food systems and supplies.

\section{Overarching Themes}

The recommendations have a global perspective. This inevitably means that many are broad but they can become more specific when adapted to national and local needs and circumstances.

The recommendations are designed as the basis of programmes and practices throughout the life course, with special emphasis given to actions that protect the short- and longterm health of children, young women, and mothers. One of the principles used when producing the recommendations was that the policies and actions need to be equitable and not widen inequities if they are implemented.

Each recommendation does not stand alone. All depend to some extent on other policies and actions being implemented. The maximum gain will result from coherent, coordinated action across all society. All actors have a responsibility to make public health, including prevention of obesity and cancer, a priority.

\section{Integrated Strategies are Needed}

Education components are important but need to be implemented as part of multifaceted programmes in order to be more effective. Interventions need to be aimed at populations, and to take account of personal characteristics such as age, sex, social and ethnic background and beliefs.

Public health policies and actions, like those recommended here, typically encompass a broad range of actions that are beyond the scope of what health ministries and health professionals can do alone. Improvement of public health, including reducing levels of obesity, cannot be achieved merely by relying on people making healthy personal choices. For example, enabling routine physical activity requires planning and transport government departments, civil engineers, architects, and employers to work together to plan, construct and adapt cities, transportation systems, buildings and offices, in ways that will improve public health.

\section{Leadership and Coordinated Action}

Governments, and through them multinational bodies, have central responsibility for the protection and improvement of public health, including prevention of obesity and cancer.

It is important to identify the opportunities and responsibilities of specific actors. However, isolated interventions rarely remain effective. Therefore, the overarching recommendation of the Policy Report is that it is essential that all relevant actors work together to prevent cancer and promote public health. In this way there is more chance that policies and actions will be effective.

\section{Further Evidence is Needed}

Climate change could potentially have a large effect on dietary patterns and therefore obesity and cancer prevention, but there is currently not enough direct or pertinent evidence for potential effective actions in order to base a recommen- 
dation. For example, more research into the impact of climate change on food security and on the risk of nutritionrelated disease, including cancer, is needed.

An evaluation component should be an integral part of all policies and actions that are implemented. Evaluation needs to be adequately resourced and designed to produce more direct evidence on the effectiveness of interventions. The findings from this can produce further evidence that can then be used to improve existing policies and actions.

\section{CONCLUSIONS}

\section{Cancer is Preventable}

Most cancers can be prevented by avoiding exposure to tobacco and by following the recommendations from the 2007 Diet and Cancer Report. A major proportion of the cancers associated with food, nutrition, physical activity, and body fatness could be prevented by avoiding overweight and obesity alone. For example, in USA around one fifth of the body fatness-related cancers could be prevented if everyone was a healthy weight. For people that do not smoke, healthy diet and physical activity patterns are particularly important.

\section{People do not Behave as Completely Free Agents}

People place high value on health but often fail to achieve it. External factors affect the availability, accessibility and affordability of healthy food and opportunities for physical activity, and therefore impact on personal choice. Conversely, changes to these external pressures could make it easier for people to choose healthy ways of life and to be a healthy weight. This is the basis of the need for policy and action.

Personally directed educational interventions are limited in their efficacy, because it is difficult to sustain activity that is substantially different to social norms. The purpose of this Report is to shift social norms by affecting the subtle but powerful external factors that influence people's behaviours, including those that affect body fatness.

Everyone in society has a role to help people live healthy lives. All relevant actors need to work together so that initiatives are more likely to be successful and have a long lasting impact. Partnerships and collaborations are essential.

\section{What Needs to Happen Next}

The current situation for each actor needs to be determined, that is, which recommendations need to be implemented or action extended. This may differ by country. Collaborations and partnerships between actors need to be formed so that actors can work together to identify priorities relevant to the local context, and implement appropriate policies and actions. The public health goals from the 2007 Diet and Cancer Report provide evidence-based benchmarks against which the success or otherwise of population-based policies can be judged.

The recommended policies and actions were designed in the context of cancer prevention, and will need to be integrated with strategies for obesity and other major disease prevention, as in general, the policies and actions recommen- ded in the Policy Report will also impact favourably on other chronic diseases.

Although more research is needed, enough is now known about how society can start to make changes to prevent obesity and cancer through food, nutrition, and physical activity. The Policy Report, and the recommended actions described in it, are a call and spur to action.

\section{REFERENCES}

[1] World Cancer Research Fund/American Institute for Cancer Research. Food, Nutrition, Physical Activity, and the Prevention of Cancer: a Global Perspective 2007. Available from: http://www.dietandcancerreport.org/er/. [Accessed date: July 2009]

[2] World Cancer Research Fund/American Institute for Cancer Research. Second expert report Food, Nutrition, Physical Activity and the Prevention of Cancer: a Global Perspective; Systematic Literature Review Specification Manual. Available from: http://www.dietandcancerreport.org/downloads/SLR_Manual.pdf [Accessed date: July 2009]

[3] World Cancer Research Fund/American Institute for Cancer Research. 2009. Policy and Action for Cancer Prevention. Food, Nutrition, Physical Activity: a Global Perspective. Available from: http://www.dietandcancerreport.org/pr/. [Accessed date: July 2009]

[4] World Health Organization. World health statistics 2006. Available from: http://www.who.int/whosis/whostat2006_10highlights.pdf [Accessed date: July 2009].

[5] Popkin BM. The World Is Fat-The Fads, Trends, Policies, and Products That Are Fattening the Human Race. New York: AveryPenguin Press 2008.

[6] World Health Organization. Obesity and overweight. Available from: http://www.who.int/mediacentre/factsheets/fs311/en/index. html

[7] World Health Organization. Are the number of cancer cases increasing or decreasing in the world? Available from: http:/www.who.int/features/qa/15/en/ [Accessed date: July 2009].

[8] Duffey KJ, Popkin BM. Shifts in patterns and consumption of beverages between 1965 and 2002. Obesity (Silver Spring) 2007; 15: 2739-47.

[9] Rivera JA, Muñoz-Hernández O, Rosas-Peralta M, et al. Beverage consumption for a healthy life: recommendations for the Mexican population. Salud Publica Mex 2008; 50: 173-95.

[10] International Agency for Research on Cancer. Globocan 2002 Available from: http://www-dep.iarc.fr/ [Access date: July 2009].

[11] Butland B, Jebb S, Kopelman P, et al. Foresight Tackling Obesities: Future Choices -Project report. Government Office for Science 2007.

[12] International Obesity TaskForce. The Causal Web. Available at: http://www.iotf.org/groups/phapo/causalweb.htm [Accessed date: July 2009].

[13] Bray GA, Nielsen SJ, Popkin BM. Consumption of high-fructose corn syrup in beverages may play a role in the epidemic of obesity. Am J Clin Nutr 2004; 79: 537-43.

[14] Cordain L, Eaton SB, Sebastian A, et al. Origins and evolution of the Western diet: health implications for the 21 st century. Am J Clin Nutr 2005; 81: 341-54.

[15] Wang Y, Thomas B, Ghebremeskel K, et al. Changes in protein and fat balance of some primary foods: implications for obesity. $6^{\text {th }}$ International Society for the Study of Fatty Acids and Lipids Congress. Brighton, 2004.

[16] Morland K, Diez Roux AV, Wing S. Supermarkets, other food stores, and obesity: the Atherosclerosis Risk in Communities Study. Am J Prev Med 2006; 30: 333-9.

[17] Wrigley N, Warm D, Margetts B. Deprivation, diet, and food-retail access: findings from the Leeds 'food deserts' study. Environ Plan A $2003 ; 35: 151-88$.

[18] Lang JE, Mercer N, Tran D, et al. Use of a supermarket shelflabeling program to educate a predominately minority community about foods that promote heart health. J Am Diet Assoc 2000; 100: 804-9.

[19] Kahn EB, Ramsey LT, Brownson RC, et al. The effectiveness of interventions to increase physical activity. A systematic review. Am J Prev Med 2002; 22: 73-107. 
[20] Cavill N, Foster C. How to promote health enhancing physical activity: community interventions. In: Oja P, Borms J, Eds. Health enhancing physical activity. London: Meyer \&Meyer Sport 2004.

[21] Ogilvie D, Egan M, Hamilton V, et al. Promoting walking and cycling as an alternative to using cars: systematic review. BMJ (Clin Res Ed) 2004; 329: 763-766. doi:10.1136.

[22] Dyson L, Renfrew M, McFadden A, et al. 2005. Promotion of Breastfeeding Initiation and Duration. National Institute for Health and Clinical Excellence. Available from: http://www.nice.org.uk/ niceMedia/pdf/EAB_Breastfeeding_final_version.pdf [Accessed date: April 2009]

[23] Kosmala-Anderson J, Wallace LM. Breastfeeding works: the role of employers in supporting women who wish to breastfeed and work in four organizations in England. J Public Health 2006; 28:183-91. doi:10.1093/pubmed/fd1012

[24] Ortiz J, McGilligan K, Kelly P. Duration of breast milk expression among working mothers enrolled in an employer sponsored lactation program. Pediatr Nurs 2004; 30: 111-9.

[25] Chopra M. Globalization and food: implications for the promotion of "healthy" diets. In: Globalization, Diets, and Noncommunicable Diseases. Geneva: World Health Organization 2002.

[26] Kinabo J. Impact of globalization on food consumption, health and nutrition in urban areas: a case study of Dar es Salaam, United Republic of Tanzania. In: Globalization of Food Systems in Developing Countries: Impact on Food Security and Nutrition. Rome: Food and Agriculture Organization of the United Nations, 2004. Available from: http://www.fao.org/docrep/007/y5736e/ y5736e00.htm [Accessed date: April 2009]

[27] Regmi A, Ballenger N, Putnam J. Globalisation and income growth promote the Mediterranean diet. Public Health Nutr 2004; 7: 97783.

[28] Kennedy G, Nantel G, Shetty P. Globalization of food systems in developing countries: a synthesis of country case studies. In: Globalization of Food Systems in Developing Countries: Impact on Food Security and Nutrition. Rome: Food and Agriculture Organization of the United Nations, 2004. Available from: http://www.fao.org/docrep/007/y5736e/y5736e00.htm [Accessed date: April 2009].

[29] Hawkes C. Uneven dietary development: linking the policies and processes of globalization with the nutrition transition, obesity and diet-related chronic diseases. Global Health 2006; 2: article 4.

[30] Willett WC, Koplan JP, Nugent R, et al. Prevention of chronic disease by means of diet and lifestyle changes. In: Jamison DT, Breman JG, Measham AR, et al., Eds. Disease Control Priorities in Developing Countries. $2^{\text {nd }}$ ed. Washington, DC: World Bank and Oxford University Press 2006. Available from: http://files. dcp2.org/pdf/DCP/DCP.pdf [Accessed date: April 2009]

[31] Gardner BL. American Agriculture in the Twentieth Century: How it Flourished and What it Cost. Cambridge, MA: Harvard University Press 2002.

[32] Brownson RC, Haire-Joshu D, Luke DA. Shaping the context of health: a review of environmental and policy approaches in the prevention of chronic diseases. Annu Rev Public Health 2006; 27 : 341-70.

[33] Glanz K, Yaroch AL. Strategies for increasing fruit and vegetable intake in grocery stores and communities: policy, pricing, and environmental change. Prev Med 2004; 39 (Suppl 2): S75-80.

[34] Goodman C, Anise A. What is Known About the Effectiveness of Economic Instruments to Reduce Consumption of Foods High in Saturated Fats and Other Energy-Dense Foods for Preventing and Treating Obesity? In: Health Evidence Network report. Copenhagen: WHO Regional Office for Europe, 2006. Available from: http://www.euro.who.int/document/E88909.pdf [Accessed date: April 2009].

[35] Henson S, SekulaW. Market reform in the Polish food sector: impact upon food consumption and nutrition. Food Policy 1994; 19: 419-42.

[36] Lock K, Gabrijelcic-Blenkus M, Martuzzi M, et al. Health impact assessment of agriculture and food policies: lessons learnt from the Republic of Slovenia. Bull World Health Organ 2003; 81: 391-8.

[37] Jacobson MF, Brownell KD. Small taxes on soft drinks and snack foods to promote health. Am J Public Health 2000; 90: 854-7.

[38] Dugdill L, Graham RC, McNair F. Exercise referral: the public health panacea for physical activity promotion? A critical perspective of exercise referral schemes; their development and evaluation. Ergonomics 2005; 48: 1390-410.
[39] Morgan O. Approaches to increase physical activity: reviewing the evidence for exercise-referral schemes. Public Health 2005; 119: 361-70.

[40] National Institute for Health and Clinical Excellence. 2006. A Rapid Review of the Effectiveness of Exercise Referral Schemes to Promote Physical Activity in Adults. Available from: http://www.nice.org.uk/nicemedia/pdf/PA-

Exercise_Referral_Review_Final_May_2006.pdf. Access date: April $200 \overline{9}$.

[41] Mhurchu CN, Gorton D. Nutrition labels and claims in New Zealand and Australia: a review of use and understanding. Aust N Z J Public Health 2007; 31: 105-12.

[42] Hastings G, Stead M, McDermott L, et al. 2003. Review of Research on the Effects of Food Promotion to Children. Food Standards Agency, UK. Available from: http://www.food.gov.uk/ multimedia/pdfs/foodpromotiontochildren1.pdf [Accessed date: April 2009].

[43] Hastings G, McDermott L, Angus K, et al. The Extent, Nature and Effects of Food Promotion to Children: A Review of the Evidence. Technical paper prepared for the World Health Organization 2006 Available from: http:/www.who.int/entity/ dietphysicalactivity/ publications/Hastings_paper_marketing.pdf [Accessed date: April 2009].

[44] Jones A, Bentham G, Foster C, et al. Tackling Obesities: Future Choices - Obesogenic Environments - Evidence Review. Foresight. Government Office for Science 2007. Available from: http://www.foresight.gov.uk/Obesity/03.pdf [Accessed date: April 2009].

[45] World Health Organization. Infant formula and related trade issues in the context of the international code of marketing of breast-milk substitutes. Available from: http://www.who.int/nutrition/ infant_formula_trade_issues_eng.pdf[Accessed date: April 2009].

[46] World Health Örganization/Ünited Nations Children's Fund. 2006. Baby- Friendly Hospital Initiative, Revised, Updated and Expanded for Integrated Care. Available from: http://www.who.int/nutrition/ publications/infantfeeding/9789241595018_s1.pdf [Accessed date: April 2009].

[47] Renfrew M, Dyson L, Wallace L, et al. Breastfeeding for Longer What Works? Systematic Review Summary. National Institute for Health and Clinical Excellence 2005. Available from: http://www.nice.org.uk/nicemedia/pdf/Breastfeeding_summary.pdf [Accessed date: April 2009].

[48] Stables GJ, Subar AF, Patterson BH, et al. Changes in vegetable and fruit consumption and awareness among US adults: results of the 1991 and 19975 A Day for Better Health Program surveys. J Am Diet Assoc 2002; 102: 809-17.

[49] National Institute for Health and Clinical Excellence. Obesity: The Prevention, Identification, Assessment and Management of Overweight and Obesity in Adults and Children 2006. Available from: http://www.nice.org.uk/Guidance/CG43 [Accessed date: April 2009]

[50] Ogilvie D, Foster CE, Rothnie $\mathrm{H}$, et al. Interventions to promote walking: systematic review. BMJ (Clin Res Ed) 2007; 334: 1204-7.

[51] Raine K, Spence JC, Church J, et al. State of the Evidence Review on Urban Health and Healthy Weights. Ottawa: Canadian Institute for Health Information 2008.

[52] Jensen JD, Smed S. Cost-effective design of economic instruments in nutrition policy. Int J Behav Nutr Phys Act 2007; 4: article10.

[53] Conforti P, Pierani P, Rizzi PL. Food and Nutrient Demands in Italy. Actual Behaviour and Forecast through a Multistage Quadratic System with Heterogeneous Preferences. Siena: Quaderni Università degli Studi di Siena, 2000.

[54] Darmon N, Ferguson EL, Briend A. A cost constraint alone has adverse effects on food selection and nutrient density: an analysis of human diets by linear programming. J Nutr 2002; 132: 3764-71.

[55] Johnson F, Cooke L, Croker H, et al. Changing perceptions of weight in Great Britain: comparison of two population surveys. BMJ (Clin Res Ed) 2008; 337: a494. Doi: 10.1136/bmj.a494.

[56] Mokhtar N, Elati J, Chabir R, et al. Diet culture and obesity in northern Africa. J Nutr 2001; 131: 887S-92S.

[57] Gill T, Hughes R, Tunidau-Schultz J, et al. Obesity in the Pacific: Too Big to Ignore. Secretariat of the Pacific Community 2002 Available from: http://www.wpro.who.int/NR/rdonlyres/ B924BFA6-A061-43AE-8DCA-0AE82A8F66D2/0/ obesityinthepacific.pdf [Accessed date: April 2009]. 
[58] Amesty SC. Barriers to physical activity in the Hispanic community. J Public Health Policy 2003; 24: 41-58.

[59] Seefeldt V, Malina RM, Clark MA. Factors affecting levels of physical activity in adults. Sports Med 2002; 32: 143-68.

[60] Sallis JF, Prochaska JJ, Taylor WC. A review of correlates of physical activity of children and adolescents. Med Sci Sports Exerc 2000; 32: 963-75.

[61] Griffiths LJ, Tate AR, Dezateux C. The contribution of parental and community ethnicity to breastfeeding practices: evidence from the Millennium Cohort Study. Int J Epidemiol 2005; 34: 1378-86.

[62] California WIC Association, UC Davis Human Lactation Center. 2006. Overcoming Barriers to Breastfeeding in Low-income Women. A Policy Brief on Preventing Obesity in Early Childhood. Available from: http://www.calwic.org/docs/reports/bf_paper2.pdf [Accessed date: April 2009].

[63] Lee MJ, Popkin BM, Kim S. The unique aspects of the nutrition transition in South Korea: the retention of healthful elements in their traditional diet. Public Health Nutr 2002; 5: 197-203.

[64] Popkin BM. Global nutrition dynamics: the world is shifting rapidly toward a diet linked with noncommunicable diseases. Am J Clin Nutr 2006; 84: 289-98.

[65] Koplan JP, Liverman CT, Kraak VA. Preventing Childhood Obesity: Health in the Balance. Institute of Medicine. Washington DC: The National Academies Press 2005.

[66] van Sluijs EM, McMinn AM, Griffin SJ. Effectiveness of interventions to promote physical activity in children and adolescents: systematic review of controlled trials. BMJ (Clin Res Ed) 2007; 335: 703-07

[67] Paineau DL, Beaufils F, Boulier A, et al. Family dietary coaching to improve nutritional intakes and body weight control: a randomized controlled trial. Arch Pediatr Adolesc Med 2008; 162: 34-43.

[68] Timperio A, Salmon J, Ball K. Evidence based strategies to promote physical activity among children, adolescents and young adults: review and update. J Sci Med Sport 2004; 7: 20-9.
[69] Pisacane A, Continisio GI, Aldinucci M, et al. A controlled trial of the father's role in breastfeeding promotion. Pediatrics 2005; 116 : e494-8.

[70] National Institute for Health and Clinical Excellence. Physical Activity and Children. Review 7 - Intervention Review: Family and Community. NICE Public Health Collaborating Centre - Physical Activity 2008. Available from: http://www.nice.org.uk/media/ C7E/3C/PromotingPhysicalActivityChildrenReview7FamilyComm unityInterventions.pdf [Accessed date: April 2009].

[71] O'Dea JA, Wilson R. Socio-cognitive and nutritional factors associated with body mass index in children and adolescents: possibilities for childhood obesity prevention. Health Educ Res 2006; 21: 796-805.

[72] O’Brien G, Davies M. Nutrition knowledge and body mass index. Health Educ Res 2007; 22: 571-5.

[73] Ciliska D, Miles E, O'Brien MA, et al. Effectiveness of community interventions to increase fruit and vegetable consumption. J Nutr Educ 2000; 32: 341-52.

[74] Bowen DJ, Beresford SA. Dietary interventions to prevent disease. Annu Rev Public Health 2002; 23: 255-86.

[75] Forster DA, McLachlan HL, Lumley J. Factors associated with breastfeeding at six months postpartum in a group of Australian women. Int Breastfeed J 2006; 1: 18.

[76] Protheroe L, Dyson L, Renfrew MJ, et al. The Effectiveness of Public Health Interventions to Promote the Initiation of Breastfeeding. Health Development Agency 2003. Available from: http://www.nice.org.uk/nicemedia/documents/breastfeeding eviden cebriefing.pdf [Accessed date: April 2009].

[77] Mauro M, Taylor V, Wharton S, et al. Barriers to obesity treatment Eur J Intern Med 2008; 19: 173-80.

[78] Trost SG, Owen N, Bauman AE, et al. Correlates of adults' participation in physical activity: review and update. Med Sci Sports Exerc 2002; 34: 1996-2001.

[79] Speck BJ, Harrell JS. Maintaining regular physical activity in women: evidence to date. J Cardiovasc Nurs 2003; 18: 282-91. 